\section{The evolving field of thyroid cancer: refinement of old and creation of new paradigms}

Ana O. Hoff'

S ince the landmark paper by Mazzaferri and Jhiang (1) indicating the benefit of adequate surgery and postoperative radioactive iodine treatment in patients with well-differentiated thyroid cancer (DTC), a lot has been learned about prognostic factors associated with disease recurrence and mortality and the risks and benefits of treatment. In addition, over the past 3 decades we have experienced a dramatic improvement in imaging and laboratorial techniques resulting in highly sensitive and specific studies for disease detection, and have observed a significant advance in the understanding of the molecular pathogenesis of thyroid cancer.

This accumulated knowledge has confirmed a few paradigms and has provided important insights that have refined the treatment of thyroid cancer. First, surgery is the mainstay treatment of thyroid cancer and therefore an experienced surgeon and an adequate surgical treatment have the highest impact in cure. Second, the major roles and best responses of radioactive iodine treatment are in reducing recurrence rate in high-risk patients and in treating young patients with micronodular lung metastases and; third, the development of kinase inhibitors has been a major breakthrough in treating metastatic thyroid cancer, not only DTC but also medullary thyroid cancer (MTC).

In this issue of Archives of Endocrinology and Metabolism three papers describe different facets of thyroid cancer treatment. On one side of the spectrum, Furtado and cols. demonstrate the low incidence of persistent (3.5\%) and recurrent disease $(2.5 \%)$ in patients with papillary thyroid cancer with less than 5 lymph nodes detected only at the operative procedure and without other poor prognostic factors (2). As expected, these patients have low risk of recurrence raising the question whether radioactive iodine treatment provides any benefit, a situation in which the disease could be less harmful than the treatment. Interestingly, in the 2009 American Thyroid Association guidelines, all patients with lymph node (LN) metastases ( $\mathrm{Nl}$ disease), regardless of number and size of LN, were considered intermediate risk and adjuvant radioactive iodine treatment was recommended (3). However, data have accumulated demonstrating that the risk of recurrence is significantly lower in patients with small LNs detected pathologically when compared to pre-operatively detected lymph nodes (4-6), findings confirmed in the study by Furtado and cols.

On the other side of the spectrum, two papers describe the "good and bad" of tyrosine kinase inhibitors. In one paper, Pitoia and cols. report a patient with advanced MTC and ectopic Cushing's syndrome in whom treatment with vandetanib resulted in rapid resolution of hypercortisolism (7). Ectopic ACTH syndrome is rarely observed in MTC but is usually associated with extensive disease and significant symptoms. The control of cortisol hypersecretion results in symptomatic relief and better quality of life. This is an important observation that has been also demonstrated with sorafenib and sunitinib and expands the known effects of kinase inihibitors. In a second
1 Departamento de Endocrinologia, Unidade de Oncologia Endócrina, Instituto do Câncer do Estado de São Paulo (ICESP), Universidade de São Paulo (USP), São Paulo, SP, Brazil

Correspondence to: Ana O. Hoff Av. Dr. Arnaldo, 251, $5^{\circ}$ andar 01246-000 - São Paulo, SP, Brazil ana.hoff@icesp.org.br ana.hoff@hc.fm.usp.br

Received on July/26/2015 Accepted on July/26/2015 DOI: 10.1590/2359-3997000000099 
paper, Pitoia and cols. report a patient with progressive iodine-refractory DTC in whom treatment with sorafenib provided partial tumor response but was associated with significant thrombocytopenia, requiring dose adjustment (8). Adverse events associated with kinase inhibitors are frequent and this report underlies the importance of being aware that unexpected side effects, such as thrombocytopenia, can also be observed.

In recent years a lot of progress has been made in the treatment of metastatic thyroid cancer. The discovery of the RET proto-oncogene and RAS mutations in MTC, mutations of RAS, BRAF, RET/PTC in DTC, as well as other molecular abnormalities that result in hyperactivation of kinase receptors and signaling pathways important for tumor cell proliferation, provided the basis for the investigation and approval of several multi-kinase inhibitors for the treatment of metastatic thyroid cancer including vandetanib and cabozantinib for MTC and sorafenib and lenvatinib for DTC (9-13). For both MTC and DTC, these therapies are associated with improvement of progression-free survival, tumor reduction and symptomatic control compared to patients treated with placebo. Despite the benefits observed in disease control, all of these drugs are associated with slightly different side-effect profiles, which makes clinical monitoring and careful management of adverse events a priority in the care of these patients. Despite the significant advances, the quest for the identification of newer therapies is still in progress, as the ideal treatment would be one associated with improvement of overall survival, less adverse effects and ultimately cure of disease.

Disclosure: no potential conflict of interest relevant to this article was reported.

\section{REFERENCES}

1. Mazzaferri EL, Jhiang SM. Long-term impact of initial surgical and medical therapy on papillary and follicular thyroid cancer. Am J Med. 1994;97(5):418-28.
2. Furtado MS, Rosario PW, Calsolari MR. Persistent and recurrent disease in patients with papillary thyroid carcinoma with clinically apparent (cN1), but not extensive, lymph node involvement and without other factors for poor prognosis. Arch Endocrinol Metab. 2015;59(4):285-91.

3. Cooper DS, Doherty GM, Haugen BR, Kloos RT, Lee SL, Mandel SJ, et al.; American Thyroid Association (ATA) Guidelines Taskforce on Thyroid Nodules and Differentiated Thyroid Cancer. Revised American Thyroid Association management guidelines for patients with thyroid nodules and differentiated thyroid cancer. Thyroid. 2009;19(11):1167-214.

4. Sugitani I, Kasai N, Fujimoto Y, Yanagisawa A. A novel classification system for patients with PTC: addition of the new variables of large ( $3 \mathrm{~cm}$ or greater) nodal metastases and reclassification during the follow-up period. Surgery. 2004;135(2):139-48.

5. Leboulleux S, Rubino C, Baudin E, Caillou B, Hartl DM, Bidart JM, et al. Prognostic factors for persistent or recurrent disease of papillary thyroid carcinoma with neck lymph node metastases and/or tumor extension beyond the thyroid capsule at initial diagnosis. J Clin Endocrinol Metab. 2005;90(10):5723-9.

6. Bardet S, Malville E, Rame JP, Babin E, Samama G, De Raucourt $D$, et al. Macroscopic lymph-node involvement and neck dissection predict lymph-node recurrence in papillary thyroid carcinoma. Eur J Endocrinol. 2008;158(4):551-60.

7. Pitoia F, Bueno F, Schmidt A, Lucas S, Cross G. Rapid response of hypercortisolism to vandetanib treatment in a patient with advanced medullary thyroid cancer and ectopic Cushing syndrome. Arch Endocrinol Metab. 2015;59(4):353-7.

8. Pitoia F, Abelleira E, Jerkovich F, Urciuoli C, Cross G. Partial response to sorafenib treatment associated with transient grade 3 thrombocytopenia in a patient with locally advanced thyroid cancer. Arch Endocrinol Metab. 2015;59(4):358-61.

9. Almeida MQ, Hoff AO. Recent advances in the molecular pathogenesis and targeted therapies of medullary thyroid carcinoma. Curr Opin Oncol. 2012;24(3):229-34.

10. Wells SA Jr, Robinson BG, Gagel RF, Dralle H, Fagin JA, Santoro $M$, et al. Vandetanib in patients with locally advanced or metastatic medullary thyroid cancer: a randomized, double-blind phase III trial. J Clin Oncol. 2012;30(2):134-41.

11. Elisei R, Schlumberger MJ, Müller SP, Schöffski P, Brose MS, Shah $\mathrm{MH}$, et al. Cabozantinib in progressive medullary thyroid cancer. J Clin Oncol. 2013;31(29):3639-46.

12. Brose MS, Nutting CM, Jarzab B, Elisei R, Siena S, Bastholt L, et al.; DECISION investigators. Sorafenib in radioactive iodinerefractory, locally advanced or metastatic differentiated thyroid cancer: a randomised, double-blind, phase 3 trial. Lancet. 2014;384(9940):319-28.

13. Schlumberger M, Tahara M, Wirth LJ, Robinson B, Brose MS, Elisei $R$, et al. Lenvatinib versus placebo in radioiodine-refractory thyroid cancer. N Engl J Med 2015;372:621-30. 